\title{
Innovation to Enhance Blended Learning Experience: Applying Google Sites in Higher Education
}

\author{
Budi Harsanto \\ University of Padjadjaran, Bandung, Indonesia \\ budi.harsanto@fe.unpad.ac.id
}

\begin{abstract}
Internet has influences numerous aspects in our life, including our learning process. Interest in the internet as a media to enhance learning experience in education operations has increased over the last decade. The recent web era termed as web 2.0. In web 2.0 era, users have the convenience to design their own website without need of learning complicated programming language. Combination between offline and online learning is known as blended learning. Innovations related with blended learning are emerging. The purposes of this paper are to elaborate the features of Google Sites that are useful for blended learning and to share users experiences from utilize Google Sites as tools of blended learning program at Faculty of Economics and Business University of Padjadjaran (FEB Unpad), Bandung, Indonesia. Users are often inhibited in creating or maintaining a website because of the complexity challenge. Google Sites, known for its tag line "create, collect and control", offers ease of use in this regard. Faculty member and student can use this tool to interact. Users experience survey was conducted involving 84 users (78 students and 6 faculty members) to elaborate response of users, both faculty members and students. Results suggest that highest agreement rate was attained that Google site is helpful in share information. The lowest aggrement rate was found in "Google site useful for online discussion".
\end{abstract}

Keywords: Blended learning, innovation, operations, learning, process

\section{Introduction}

Internet has changed many aspects of life nowadays. Internet stands for interconnection networking, which is a network that connects computers globally. At first, in 1957 this computer network was developed for the limited purposes of the military. The internet term was raised by the Arpanet (Advanced Research Projects Agency Network) in 1974. Internet continues to grow until now. In 1995, Yahoo was established and Amazon sold books online for the first time. In 1997, Google search engine was launched. Then in 2004, Facebook was released. An important milestone occured in 1989 when Tim Berners Lee proposed management informations system called the World Wide Web, to be used by researchers at CERN, Geneva. CERN is the European Organization for Nuclear Research. In that year, the first website in the world was born. The website address was http://info.cern.ch/. Tim's idea was to ensure that information can be easily transferred using the internet. This idea could be realized and has continued to grow in the following years. Nowadays, thousands of websites are available in the virtual world with an estimated more than 2.1 billion internet users worldwide in 2011 (Gribin, 2011). Currently, internet use has been widespread in various field of life, from business to education.Web era has evolved from the beginning to the present. The first era of the web is called web 1.0 whereby the main function of web is to access information. People can access information easily, although the information was in place that are geographically far apart. Events in one place can be widely known even with slight time differences. This era really make great changes to the world. In web 1.0 users can access the information contained on the website. Relationship formed is one way. The typical website in this generation is read function. Typical website in this era is static whereby information retrieval functions is available without user interaction.The second web era is known as web 2.0. The typical website in this era is read and write. Relationship formed is two way. Technically, there are many differences between web 1.0 and web 2.0. The main difference is on the level of interaction. Web 2.0 is marked with greater interaction, enrichrelationship between people and information. In this web era, sharing takes place in mutual collaboration.

Furthermore, in web 2.0 era, users have the convenience to design their own website without need to learn a complicated programming language.In the education field, the advancement of the internet and web are very pronounced in learning process. Traditionally, learning can only takes place face to face, but 
now learning can occur without any direct human interaction. This type of learning is known as electronic learning or e-learning. E-learning can be defined as instruction delivered through any electronic media including the internet, intranets, extranets, satellite broadcast, audio/video tape, interactive TV, and CDROM (Govindasamy, 2002). In the meantime and in the future, e-learning will play an important role. Elearning transform education because it allows efficient material delivery or enhance learning interest over traditional approaches to those seriously committed in enhancing teaching and learning (Garrison \& Anderson, 2003). In education arena, learning management system (LMS) or course management system (CMS) becomes popular term in managing learning process. One of the main problems on e-learning is the lack of full participation to the completion of the course (Rodrigues, Sabino, \& Zhou, 2011). Results of the study Yueh \& Hsu (2008), found that the main barrier limiting the use of LMS in universities is the fear of technology. The professor or other faculty members often feel that they do not have the time to learn how to operate the LMS. Therefore, in the era of web 2.0 there has been a growing use of other tools beside LMS or CMS that are more user-friendly such as social networks and blogs. Blog is a website that allows easy update and interactions between administrator and users. In practice, e-learning may present as pure $100 \%$ e-learning or blended, depending on the organizational needs. One of the blogs that have been tested and implemented in blended learning program at Faculty of Economics and Business, University of Padjadjaran (FEB UNPAD) is Google Sites. This tool is considered simple and convenient that is suitable for faculty member needs with bustling activities. Based on the research background, two research questions are proposed: a) what are the features of Google Sites useful for blended learning? And b) what are the users (faculty and students) response to the implementation of Google Sites as a medium for blended learning in FEB UNPAD.

\section{Literature Review}

The advancement of information technology impacts on learning process. In the past, the learning process can only be done by in the classroom allowing face to face interaction. Nowadays, learning is commonly done with the use of the internet media. E-learning is defined as learning which is enabled by the use of internet, intranets, and other electronic networks as well as the development, delivery, and evaluation of content provided to learners through these networks (Hartley, 2001). The essential key words in this definition are network and content. A full implementation of e-learning will certainly require an application to integrate contents available on the network. According to Cambridge Advanced Learner's Dictionary \& Thesaurus in Cambridge Dictionary Online, e-learning is defined as the business of providing courses on the internet for students allowing them to study and learn at home. E-learning, refers to learning through the internet, providing students with flexible and personalized way to learn by offering learning on demand opportunities, reducing learning cost, and affecting the way of learning in the new millennium (Zhang, 2003). The debate regarding the implementation of e-learning has been going on for a long time. Johnstone (1993) found that application of appropriate educational technology in learning process is one of the key solution in addressing some important issues in education, include: financial strains on colleges and universities, financial strains on parents and students, coming of college age and inadequate learning in the undergraduate years of college. On the other hand, Alexander \& McKenzie conducted study to 104 of total 173 projects funded by Committee for the Advancement of University Teaching (CAUT) in 1994-1995. It was found that factors contributing to unsuccessful learning outcome includes: overly high ambitions in terms of desired outcomes for the budget and time available, utilization of particular information technologies that lacks of appropriate learning design, failure to recognize the importance of the project's context of implementation; commencement of software development without adequate planning, lack of access to adequate technical knowledge, skill and expertise and etc(Alexander \& McKenzie, 1998).

The practices of e-learning have some advantages and disadvantages. The advantages of e-learning are reducing travel and related costs, enabling learning at any time and any place, providing just in time learning, leveraging existing infrastructure, enabling delivery independent of platform, proving tools for tracking and record keeping and allowing for easy information updates. On the other hand, the disadvantages of e-learning includes: requiring substantial technical infrastructure, adopting new learning methods, requiring a team to design, develop and deploy, requires managmement of resources beyond the training organization, involving significant financial resources and time for organization to embrace new ways of thinking (Driscoll, 2002). Another study stated that the benefits of e-learning are primarily include flexibility, cost and breadth of coverage. The research also found that creatingorganizational readiness is an important factor in fully exploited the e-learning program implementation (Macpherson, Elliot, Harris, \& Homan, 2004). Can e-learning replace classroom learning? 
With the advantages of e-learning, e-learning can be alternative and complementary to traditional classroom. E-learning offers learner-centered and self-paced way of learning; time and location flexibility, cost-effectiveness for learners, availably to global audience; unlimited access to knowledge and archival capability for knowledge reuse and sharing. However there are some drawbacks of e-learning that involve: lack of immediate feedback in asynchronous e-learning, increased preparation time for the instructor, lack of comfort to some people which potentially creates frustration, anxiety and confusion. Traditional classroom also has its advantages, promoting immediate feedback, increasing interaction between lecturer and students, cultivating a social community. However, traditional classroom learning is a lecturer centered, with time and location constraints, and more expensive to deliver (Zhang, Zhao, Zhou, \& Nunamaker, 2004).

In e-learning implementation, some things need to be considered: adding value to both formal and non formal for users involved in it, using blended learning to train behaviour, creating organization initiative and allowing the users to be the main actors in the program (Wahono, 2008). Therefore, implementation of e-learning needs adequate planning and preparation to run successfully. Integration between offline and online learning is known as blended learning. Blended learning can strongly enrich instructional approaches such as lectures, labs or field work (Handal, Groenlund, \& Gerzina, 2010). Application of blended learning in problem-based learning or PBL was also studied by the researchers. E-learning can be divided into synchronous communication and asynchronous communication. The first type takes place live while the second type is not. The use of blended PBL or bPBL has been proven to positively affect the ratings given students to the course (Moeller, Spitzer, \& Spreckelsen, 2010). Gunasekaran, McNeil, \& Shaul (2002) argued that e-learning through internet can be applied to various fields covering arts, business, engineering, science, medicines, agriculture, law and justice. In its implementation, it is undeniable that e-learning courses has high dropout rate as Levy (2007) study reported that dropout students have lower satisfaction with e-learning than students who successfully completed the same elearning courses. For successful implementation, pedagogical attributes should be noted includes five parameters namely: developing content, storing and managing content, packaging content, student support and assessment (Govindasamy, 2002).

Learning Management System (LMS) is useful as a platform to support e-learning or blended learning. LMS is often referred to as Course Management System (CMS). There is a commercial LMS provided such Blackboard, Intralearn or Desire2Learn, and open source LMS like Moodle. A number univerisities also develop customized LMS specifically designed for their university purposes. However, the use of LMS in universities has not fully involved all faculty members and students. Interesting to see the behaviour of LMS users. A survey on 862 faculty members at 38 institutions who utilized Blackboard LMS indicates that faculty primarily used LMS as a course administration tools to allow course document available to students while the interactive features were largely unused (Woods, Baker, \& Hopper, 2004). The research also showed that women had more positive attitudes than men in terms of classroom management and therefore enhance a positive relational climate. Other research undertaken by Yueh \& Hsu (2008) also presented similar results. 182 professors who use LMS named CEIBA at National Taiwan University (NTU) shows that the utilisation of the knowledge function in the LMS is much higher than the interaction function.

Table 1: LMS utilization level at NTU

\begin{tabular}{lll}
\hline Category & Functions & Level of use \\
\hline Knowledge & Course objectives and evaluation & $96 \%$ \\
Knowledge & Student information and roster & $95 \%$ \\
Knowledge & FTP files to CEIBA & $95 \%$ \\
Knowledge & Announcement boards & $90 \%$ \\
Knowledge & Using template to create course pages & $86 \%$ \\
Knowledge & Email to all student & $85 \%$ \\
Interaction & Discussion board & $66 \%$ \\
Interaction & Homework assignment & $60 \%$ \\
Interaction & Resource sharing & $58 \%$ \\
Interaction & Co-teacher management & $45 \%$ \\
Interaction & Grouping students & $43 \%$ \\
Interaction & Homework sharing & $37 \%$ \\
Interaction & Chat rooms & $35 \%$ \\
Interaction & Voting & $34 \%$ \\
\hline
\end{tabular}

Source: Yueh \& Hsu, 2008 
Further development of e-learning is mobile learning or m-learning where development of devices and technology allows for implementation of m-learning with main types of mobile devices used in education such as: notebook, tablet, PDA, cellular phones and smart phones (Georgiev, Georgieva, \& Smrikarov, 2004). Through scientific development, e-learning has also built the discipline through the science of elearning involving studies on how people learn in electronic learning environments with three elements of e-learning. These three elements are evidence, theory and application. Evidence acts as the basic of replicated findings from rigorous and appropriate research studies, whereas theory is research based theory of how individuals learn in electronic learning environments. Application acts as theory based principles in designing electronic learning environments which can be tested in research studies (Mayer, 2003).

\section{Methodology}

This research employs a descriptive method to describe the two main goals. First, the study explores and explains the function and features of Google Sites when implemented as a blended learning tool. In order to achieve this goal, features in Google Sites related to the learning purposes in higher education were explored. Secondly, the study describes user's response after using the aforementioned tools. Survey was performed towards the internet users (students and faculty members) to understand user's response. Using Google questionnaire, research respondents were asked to provide score and assess their experiences using Likert scale of 1 to 5 . Research statements included in the questionnaire were developed and modified from study done by Rodrigues, Sabino, \& Zhou (2011). The target study population of the survey are students and faculty members who enroll in e-learning program as part of their undergraduate study in FEB Unpad in Odd Semester 2012/2013. The fact that the e-learning program is optional in nature, not every subject is equipped with e-learning this program. There are 10 subjects offering e-learning program, involving 10 faculty members and approximately 250 students. Since the participation in the survey is voluntary, convenience sampling was done through the announcement of the users of e-learning faculty to students who enrolled in odd semester 2012/2013 intake. Sampling was done on 84 e-learning users consisting of 6 faculty members and 78 students. Survey on user's experience was distributed using online questionnaires through the use of Google form.

\section{Results and Discussion}

Google Sites Feature Elaboration for Learning Purposes: At university level, the LMS used at University of Padjadjaran (Unpad) Indonesia is Moodle. Previous LMS being used is WebCT. In faculty level, Faculty of Economics and Business University of Padjadjaran (FEB Unpad) try to use application called Google Sites. Google Sites is one of the Google products as tools to create website. E-learning policy at FEB Unpad is integrated learning. E-learning program at FEB Unpad defined as the process of learning that complement face to face meetings, allowing online interaction between faculty members and users such as lecture materials delivery, announcements posting or online discussions. As another Google products that knows for its simplicity, Google Sites offers a user friendly and relatively easy dashboard to be used by general users. With the use this application, the expected fear of technology can be reduced. Although Google Sites is not designed specifically for e-learning purposes, Google Sites can be utilized for e-learning purposes.

Figure 1: Google Sites concept

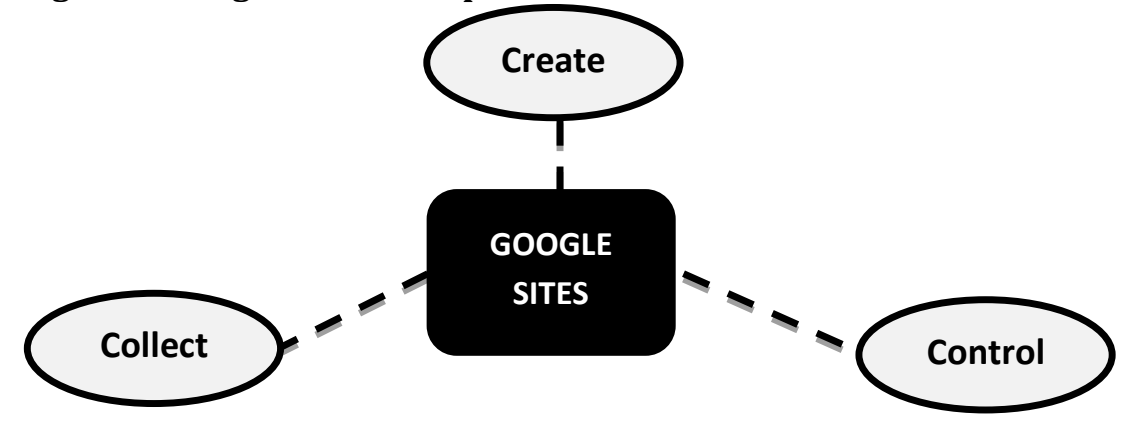

Faculty members can take advantages of Google Sites since this application can be easily created and managed. This sites is very suitable for faculty members with numerous activities. Quite often, busy users stops along the way in creating or maintaining a website because of the complexity challenge. Google 
Sites, with the motto: create, collect and control, offers ease in this matter. Lecturers and students can use Google Sites as a simple and valuable tool to interactthrough the internet. Google Sites does not require any programming language, that is complicated for layman. Google Sites becomes an interesting tool to be utililized for several reasons including: Google sites is free, ensuringthe sustainability at minimal cost; easy to create and maintain; allows user collaboration; compatible with other Google products; and searcheable on Google search engineetc. In order to use Google Sites in FEB Unpad environment, login is required for faculty members using their official accounts. When faculty members FEB Unpad access the site, it will spesifically addressed using extension /a/fe.unpad.ac.id. Google Sites have dashboard that serves as 'back office' for e-learning website. The four main buttons appear at the top of the page are: edit page, new page, more, and sharing. Edit page is used to edit the active page. New page is used to create a new page. More button contains variety of menus including: recent site activity, pages, attachments, apps scripts, deleted items, general, sharing and permissions, adsense, colors and fonts and themens. Sharing is a shortcut for sharing and permissions function.

\section{Figure 2: The appearance of Google Sitesfor e-learning purpose}

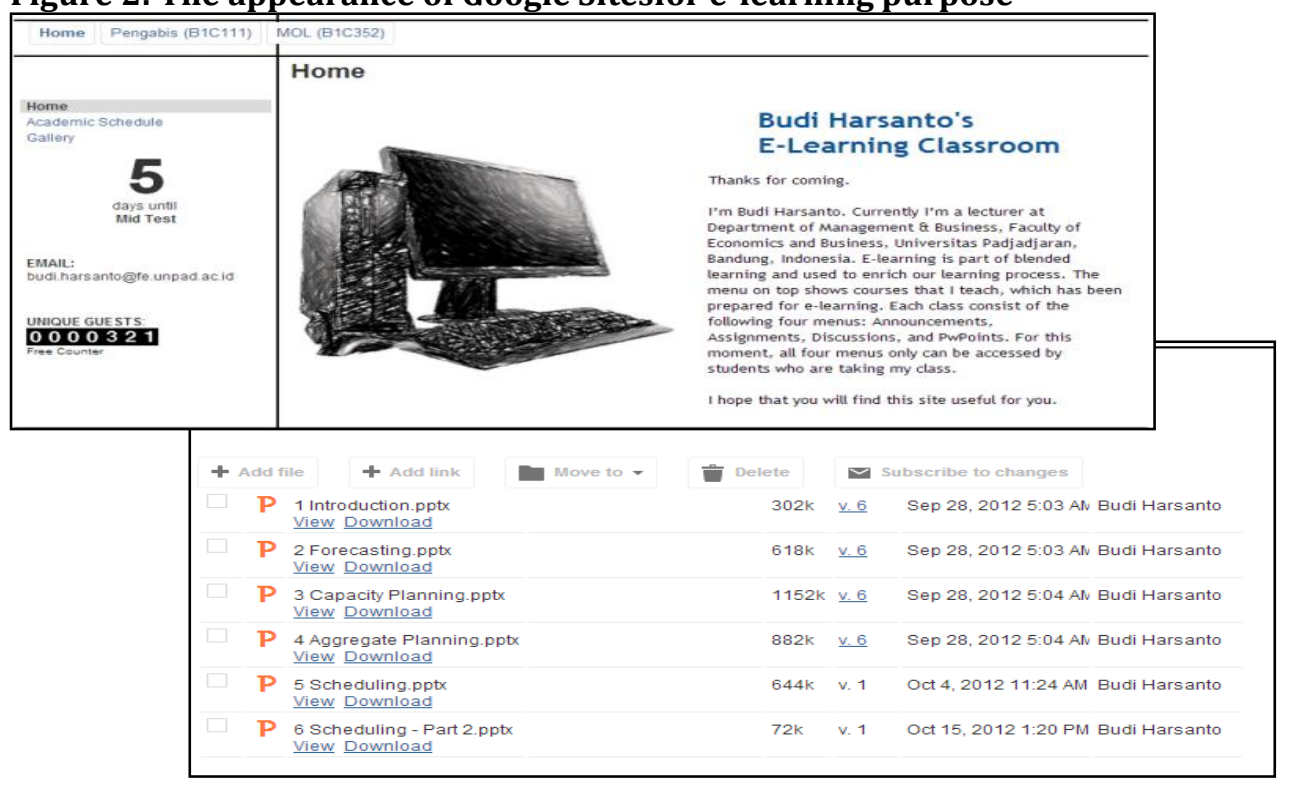

From the experience of using Google Sites, below are powerful features of e-learning :

File-Cabinet page templates. One of the most preferred functions in Google site is storage of lecture materials. This is accomodated by Google Sites through this template. In this template, faculty members can upload document to the site which is available for download by the visitors. Beside lecture materials, this template is also suitable for submitting student tasks.

Announcement page templates. Announcement page templates is a mini blog which is arranged chronologically by posting time. This template can be used to create new announcements, update information, or provide assignments for students. With this template, users can stay connected to updated information related to the learning process.

Sharing \& permissions setting. This function is very useful feature of Google Sites whereby faculty members as administrator have the option to set an e-learning site to be open for public, private and combinations between the two. When it is set as open to public, anyone can find and view materials, without sign-in requirement; however, when it is set as private, only those with granted permission can access the materials after signing in.

Full compatibility with other google product. As one of Google's product, Google Sites has full compatibility with other Google products. Google Sites will be more powerful when combined with Gmail, Google Groups, Google Calendar, YouTube, Google Drive (Google Docs), and other related Google products.

Site layout, themes and page hierarchy. As applied in websites or blogs, site layout feature helps faculty members to manage the site layout according to their needs and goals; themes can be used to decorate the sites making it more interesting for the users; page hierarcy feature helps to structure the relationship between the pages. Overall, these three features allow a systematic and attractive website development. Shown in table 2 below are the features in Google Sites which can be utilized in e-learning implementation. 
Figure 3: Google Sites Compatibility

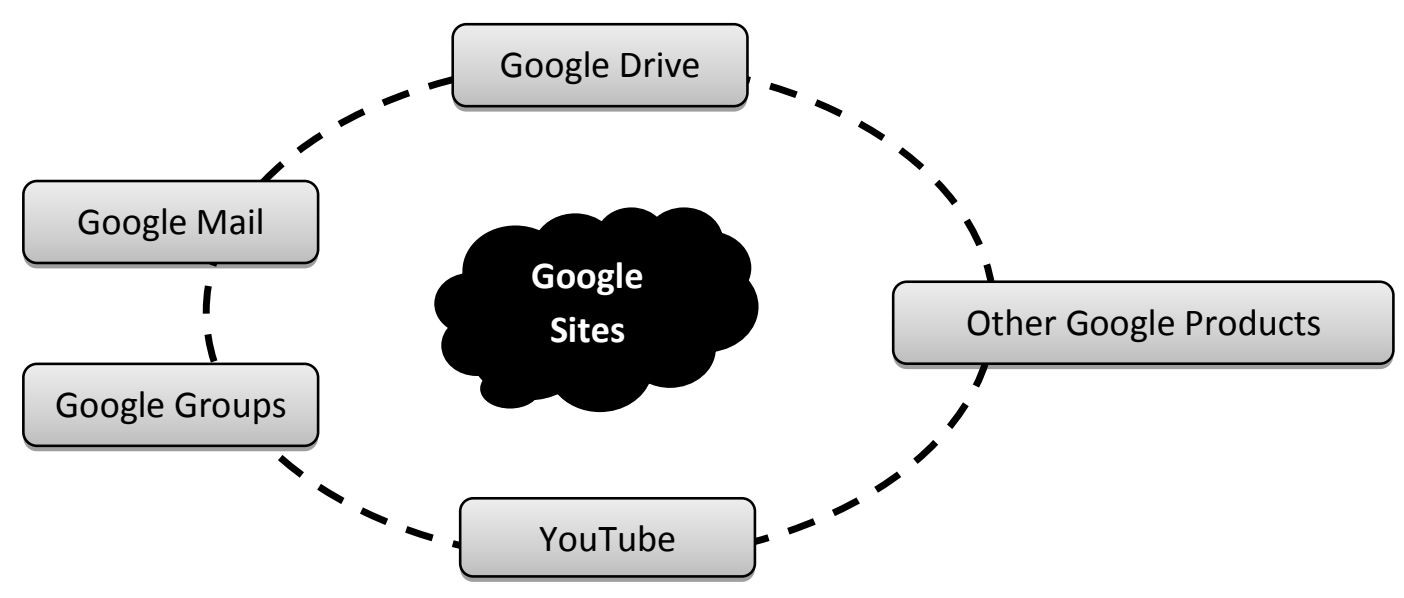

Table 2: Summary of Google Sites features for e-learning purpose

\begin{tabular}{ll}
\hline Item & Features \\
\hline Announcements & Announcement page template \\
Lecture materials & File cabinet page template \\
Assignment/Quizzes & Ability to link to Google Drive \\
Course content (syllabus, course description) & Web page template \\
Sharing and permission & Ability to connect to Google Groups \\
Discussion forums & Allowing interactive comments \\
Calendar of events & Linked to Google Calendar \\
\hline
\end{tabular}

Users Experience Survey: The use of Google Sites at FEB Unpad has recently been implemented for the past 3 semesters. From the faculty member point of view, the recent use of Google Sites is not compulsory. In this semester, 10 courses have used Google Sites. A simple survey was conducted to find out the feedback from users, both faculty members and students. A survey was carried out involving 84 user participants, consisting of 78 students at FEB Unpad and 6 faculty members. The respondents were asked to fill a questionnaire containing some survey statements to reflect their experience after using Google Sites. The survey uses Likert scale 1-5 and the survey statements/indicators are shown in Table 3.

Table 3: User experience survey statements

\begin{tabular}{ll}
\hline statement 1 & Google Sites design is attractive \\
\hline statement 2 & Google Sites is helpful to share information \\
statement 3 & Google Sites feature is easy to use and well functioned \\
statement 4 & The 'sharing and permissions' setting is reliable to use \\
statement 5 & Google Sites is useful for online discussions \\
statement 6 & I am satisfied after using Google Sites \\
\hline
\end{tabular}

Figure 4: Survey results for students

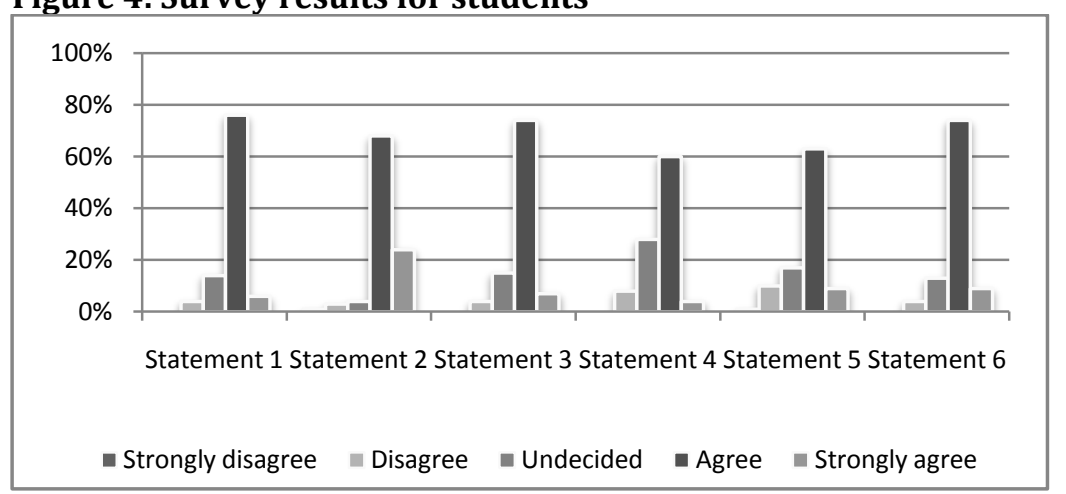

Figure 4 presents the results upon survey the students. It can be observed that $76 \%$ of the students being surveyed agree that the design is attractive. $68 \%$ of them agree and $24 \%$ strongly agree that it is helpful 
to share information. The majority of the students, accounting for $74 \%$ agree that feature easy to use and well functioned, whereas only $28 \%$ undecide whether sharing and permission setting is reliable to use. From the total participants, $10 \%$ disagree that it is useful for online discussion. Overall, around $75 \%$ of the respondents feel satisfied after use Google Sites. Figure 5 shows the results upon surveying faculty members. As demonstrated in the above figure, $100 \%$ of respondents agree that the Google design is attractive. Whereby half of the respondents (50\%) agrees and 50\% strongly agree that it is helpful to share information.In terms of ease of use and performance, approximately $33 \%$ of respondents agree and $33 \%$ strongly agree that the features offered are easy to use and well functioned. Moreover, $68 \%$ of the survey participants agreethat sharing and permission setting is reliable to use. Only $17 \%$ of the participants agree that it is useful for online discussions. Lastly, the survey also suggested that half of faculty member respondent agree and around 30\% strongly agree that they feel satisfied with application. From the results, the highest agreement rate was attained on the use of Google site in helping to share information. Meanwhile, the lowest percentage was observed in the use of Google for online discussion.

\section{Figure 5: Survey results for faculty members}

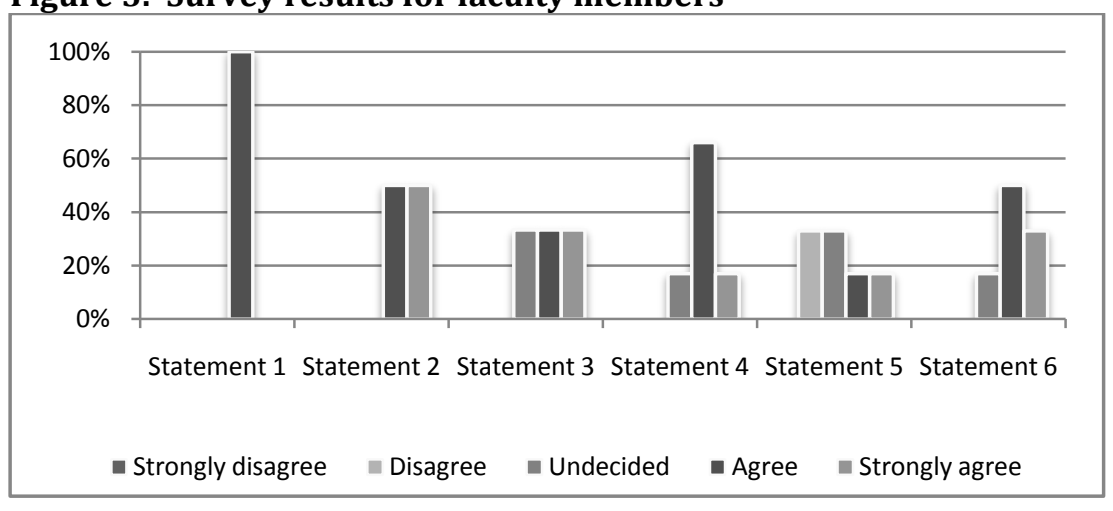

\section{Conclusion}

Learning process has currently shifted into the utilization of online technology, either totally or partially. The use of LMS, CMS, social networks or blog has evolved in such a way that allows e-learning. Results suggested that for e-learning users, the knowledge function of e-learning is preferred to the interaction function. In the education field, especially universities, one of main barriers of the utilization of e-learning application is the fear of failure in adopting new technology. Universitas Padjadjaran has trialed WebCT and currently running on Moodle as LMS. Beside Moodle, in the faculty level, FEB Unpad has also used a developed Google Sites. Google Sites were chosen for its easy to use and sustainability reasons. Implementation Google Sites for e-learning purpose in FEB Unpad is relatively new that require further observation. However, early indications from survey shows that users, both faculty members or students, involved in e-learning program enjoys these e-learning tools. Elaboration to optimize the features available in Google Sites will be useful in future research for deeper understanding. A greater scope of survey may be considered as a future research direction.

Acknowledgment: Author would like to thank to the anonymous reviewers for insightful comments and valuable suggestions for improvement.

\section{References}

Alexander, S. \& McKenzie, J. (1998). An Evaluation of IT Projects for University Learning.

Cambridge Dictionary Online. (2011). Cambridge University Press. Retrieved October 14, 2012, from http://dictionary.cambridge.org/dictionary/british/e-learning

Driscoll, M. (2002). Web-based Training: creating e-learning experiences (2nd Ed.). San Fransisco: JosseyBass/Pfeiffer.

Garrison, D. R. \& Anderson, T. (2003). E-Learning in the 21st century a framework for research and practice. Routledge.

Georgiev, T., Georgieva, E. \& Smrikarov, A. (2004). M-Learning - a New Stage of E -Learning, 1-5.

Govindasamy, T. (2002). Successful implementation of e-Learning. Pedagogical considerations, 4, 287299. 
Gribin, A. (2011). A Brief History of The Internet. New Statesman, 30.

Gunasekaran, A., McNeil, R. D. \& Shaul, D. (2002). E-learning: research and applications. Industrial and Commercial Training, 34(2), 44-53. doi:10.1108/00197850210417528

Handal, B., Groenlund, C. \& Gerzina, T. (2010). Dentistry students' perceptions of learning management systems. European Journal of Dental Education: Official Journal of the Association for Dental Education in Europe, 14(1), 50-4. doi:10.1111/j.1600-0579.2009.00591.x

Hartley, D. E. (2001). Selling E-Learning. Alexandria: American Society for Training \& Development.

Johnstone, D. B. (1993). Learning Productivity: A New Imperative for American Higher Education. Studies in Public Higher Education, 3(37).

Levy, Y. (2007). Comparing dropouts and persistence in e-learning courses. Computers \& Education, 48, 185-204. doi:10.1016/j.compedu.2004.12.004

Macpherson, A., Elliot, M., Harris, I. \& Homan, G. (2004). E-learning: reflections and evaluation of corporate programmes. Human Resource Development International, 7(3), 295-313. doi:10.1080/13678860310001630638

Mayer, R. E. (2003). Elements of a Science of E-Learning. Journal of Educational Computing Research, 29(3), 297-313. doi:10.2190/YJLG-09F9-XKAX-753D

Moeller, S., Spitzer, K. \& Spreckelsen, C. (2010). How to configure blended problem based learning-results of a randomized trial. Medical Teacher, 32(8), e328-46. doi:10.3109/0142159X.2010.490860

Rodrigues, J. J. P. C., Sabino, F. M. R. \& Zhou, L. (2011). Enhancing e-learning experience with online social networks. IET Communications, 5(8), 1147. doi:10.1049/iet-com.2010.0409

Wahono, R. S. (2008). Meluruskan Salah Kaprah Tentang E-Learning. Retrieved October 14, 2012, from http://romisatriawahono.net/2008/01/23/meluruskan-salah-kaprah-tentang-e-learning/

Woods, R., Baker, J. D. \& Hopper, D. (2004). Hybrid structures: Faculty use and perception of webbasedcourseware as asupplement to face-to-faceinstruction. The Internet and Higher Education, 7(4th Quarter), 281-297.

Yueh, H. P. \& Hsu, S. (2008). Designing a learning management system to support instruction. Communications of the ACM, 51(4), 59-64.

Zhang, D. (2003). Powering E-Learning In the New Millennium : An Overview of E-Learning and Enabling Technology.

Zhang, D., Zhao, J. L., Zhou, L., \& Nunamaker, J. F. (2004). Can E-Learning Replace Classroom Learning? Communications of the ACM, 47(5), 74-79. 